\title{
Seroprevalence of cytomegalovirus infection in France in 2010
}

\author{
D. ANTONA*, A. LEPOUTRE, L. FONTENEAU, C. BAUDON, \\ F. HALFTERMEYER-ZHOU, Y. LE STRAT AND D. LÉVY-BRUHL
}

Infectious diseases, Santé publique France, Saint Maurice, France

Received 18 October 2016; Final revision 7 December 2016; Accepted 28 December 2016;

first published online 7 February 2017

\section{SUMMARY}

Cytomegalovirus (CMV) infection remains the leading cause of congenital virus infection in developed countries. Measuring the national prevalence of this infection, especially among women of childbearing age, is of great value to estimate the risk of congenital CMV infection, as well as to identify risk groups that should be targeted for behavioural interventions and/or vaccination once a CMV vaccine finally becomes available. In order to fulfil these objectives, a seroprevalence survey was conducted in 2010 , using a nationally representative, population-based sample of 2536 people aged between 15 and 49 years, living in metropolitan France and attending private microbiological laboratories for blood testing. All blood samples were analysed in the same laboratory and screened for CMV-specific IgG using an enzyme-linked immunoassay technique (Elisa PKS Medac Enzyme immunoassay). The overall point estimate of CMV infection seroprevalence for individuals aged $15-49$ years was $41.9 \%$. The estimates were higher in women than in men (respectively $45.6 \%$ and $39.3 \%$ ), and people born in a non-Western country were more likely to be CMV seropositive than those born in France or in another Western country $(93.7 \%$ vs. $37.7 \%)$. Our results showed that a substantial percentage of women of childbearing age in France are CMV seronegative and therefore at risk of primary CMV infection during pregnancy. Educational measures and future vaccine are key issues to prevent infection in pregnant women and congenital CMV disease.

Key words: Cytomegalovirus, France, seroprevalence.

\section{INTRODUCTION}

The human cytomegalovirus (CMV) belongs to the Herpesviridae family and is endemic worldwide [1]. It is transmitted through intimate contact with CMV-infected body fluids of individuals with symptomatic or asymptomatic CMV infection and replicates only in human cells [1-4]. Most CMV

\footnotetext{
* Author for correspondence: Dr D. Antona, Santé publique France, Saint Maurice, France.

(Email: denise.antona@santepubliquefrance.fr)
}

infections are mild or asymptomatic in immunocompetent individuals although a mononucleosis syndrome is observed in $10 \%$ of infected cases [5]. However, CMV can produce severe disease in immunocompromised individuals and foetuses. As observed with other herpesviruses, CMV may become latent after primary infection, leading to later reactivation and disease, particularly in a context of immune suppression. Individuals with a higher incidence of primary infection include breastfed infants [6], toddlers, care providers in pre-school day-care settings $[7,8]$ and sexually active adolescents $[9,10]$. 
From a public health perspective, the most important medical impact of CMV is the damage caused to a foetus when infection occurs in utero. In Western countries, CMV remains the leading cause of congenital infection among new-borns, which may lead to permanent disabilities, such as hearing loss, intellectual disability, psychomotor delay, speech and language disabilities, behavioural disorders, visual impairment and cerebral palsy [11, 12]. A foetus is at great risk of CMV infection when a mother has a primary infection during pregnancy $[1,13]$. But due to possible maternal CMV reactivation or reinfection with a different CMV strain, the risk of foetal infection still remains in women who were CMV seropositive before pregnancy, although the transmission risk is much smaller than for primary infection $(0 \cdot 2 \%$ $2 \%$ vs 30\%-50\%) [1, 14]. Furthermore, recent studies [15-17] showed that symptomatic infection might occur with similar frequency in children born to CMV seroimmune women. Surprisingly, the highest birth prevalence rates of congenital CMV infection are found in populations with nearly $100 \%$ seroprevalence, ranging from $0.3 \%$ in population with $30 \%$ seroprevalence to about $2 \%$ in populations with $98 \%$ seroprevalence $[1,17]$. This paradox may be explained by a higher force of infection in highly seroimmune populations, with a risk of re-infection possibly outweighing the protective effect of maternal immunity on transplacental transmission and severe disease [18].

Measuring national prevalence, especially among women of childbearing age, is important in order to establish accurate estimates of the risk of congenital CMV infection, as well as to identify risk groups that should be targeted for behavioural interventions and/or vaccination once a CMV vaccine finally becomes available $[19,20]$. After primary infection, CMV-IgG seropositivity remains for life; therefore, CMV-IgG seroprevalence reflects the primary infections cumulated over time. In 2010, we conducted a national cross-sectional sero-epidemiological survey in metropolitan France, targeted at ten diseases including CMV infection (five vaccine-preventable diseases: measles, rubella, mumps, varicella and hepatitis A, and five other infectious diseases: toxoplasmosis, CMV, herpes simplex virus types 1 and 2, and hepatitis E infections) [21]. Few seroprevalence surveys on CMV infection had previously been conducted in France, and were targeted to specific population subgroups including pregnant women $[22,23]$ and hospital employees [24], surveyed in a limited number of university hospitals.

\section{METHODS}

The present study's objectives were to provide current estimates of CMV seroprevalence in France and describe individual characteristics associated with seropositive status.

\section{Population of interest}

The population of interest was restricted to people aged between 15 and 49 years, living in metropolitan France and attending private microbiological laboratories for blood testing.

\section{Sample size}

The sample size was calculated according to an expected CMV seroprevalence of $50 \%$, derived from previous surveys [21-24], with a precision set at 5\% and a type I error of $0 \cdot 05$. A design effect equal to $1 \cdot 5$ was chosen, based on the value observed in a similar seroprevalence survey conducted in 1998 [25]. The necessary sample size was estimated therefore at 2500 individuals.

\section{Sampling design}

We used a two-stage stratified sampling design. First, we built a national sampling frame of private outpatient microbiology laboratories, stratified by geographical regions and laboratory activity (number of patients and ratio of children/adults tested annually). At the first stage, we randomly selected laboratories using simple random sampling in each of the strata obtained (31 in total). At the second stage, patients coming to the laboratory for a blood test and eligible for the survey were consecutively selected and included, after signing an informed consent form (signature of legal representatives for those under 18). A dedicated laboratory staff member conducted questionnairebased interviews, and proposed collecting a supplementary blood sample. Patients having had a blood transfusion in the previous 3 months, those immunocompromised, those on immunosuppressive therapy and pregnant women coming for follow-up after having been found seronegative for one of the antigens of interest were not included in our study [21].

\section{Measures}

Variables of interest included sex, age, birthplace (country), household education level (elementary/ middle school, high school diploma or third-level college/university diploma/degree), employment status, household socio-professional category, insurance 
status (covered or not covered by complementary health insurance) and place of residence.

\section{Statistical analysis}

A sampling weight was associated with each individual, calculated as the inverse of inclusion. All statistical analyses were performed using Stata version 12.0 (StataCorp, College Station, Texas, USA) taking into account the sampling design. We improved the estimates by post-stratification on age groups, sex and geographical regions according to the 2008 French census data.

Variables which had a $P$-value of $<0 \cdot 20$ in univariate analysis were retained for multivariate analysis (except the variable 'socio-professional category', which was forced into the model). We used a Poisson regression model to assess the association between CMV seropositivity and demographic factors while adjusting for multiple covariates and estimated adjusted prevalence ratios [26]. We studied first-order interactions for statistical significance, epidemiologic plausibility and the impact of their inclusion on the other model parameters. We used the $F$ test to assess the statistical significance of variables and interactions in the model and the model fit. Variables with a $P$-value $<0.05$ were retained in the final model.

\section{Serological testing}

All samples were tested in the same laboratory (Biomnis, Lyon). Serum samples were screened for CMV-specific IgG antibodies with the CMV IgG Elisa PKS Medac enzyme immunoassay, using a BEP III Dade Behring robot, with the following testing method characteristics: sensitivity $100 \%$, specificity $97 \%$ and a positive threshold $>0.8$ universal arbitrary units per millilitre (UA/ml).

\section{Ethical and financial aspects}

The survey protocol was reviewed and approved by a national institutional and ethical review board (Comité consultatif de traitement de l'information en matière de recherche dans la santé) on 18 December 2008 ( $\left.\mathrm{N}^{\circ} 08-582\right)$. The field survey and the serological analysis were funded exclusively by Santé publique France (the French National Public Health agency).

\section{RESULTS}

A total of 2536 individuals aged 15-49 years were included in the survey; the male/female sex ratio was 0.94 (1230/1306), and median age was 27 years.
The overall point estimate of CMV infection seroprevalence for individuals aged 15-49 years was $41 \cdot 9 \%$ (95\% CI 38.4-45.5) (Table 1).

In a univariate analysis, CMV seropositivity was significantly associated with female sex, older age, non-Western birthplace, lower education level and residence in the Paris or South-East regions (Table 1).

The CMV prevalence estimates were $45 \cdot 6 \%$ (95\% CI $40 \cdot 9-60 \cdot 3)$ in women compared with $39 \cdot 3 \%$ (95\% CI $34.9-43.8)$ in men $(P=0.03)$. The estimates ranged from $28 \cdot 8 \%(95 \%$ CI $25 \cdot 1-32 \cdot 8)$ to $44 \cdot 4 \%(95 \%$ CI $39 \cdot 0-49 \cdot 8)$ and $47 \cdot 6 \%(95 \%$ CI $43 \cdot 2-52 \cdot 1)$, respectively, in the 15-24, 25-34 and 35-49 age groups $(P=0 \cdot 000)$.

People born in a non-Western country were more likely to be CMV seropositive compared with those born in France or in another Western country, with an estimated seroprevalence of $93.7 \%(95 \%$ CI $83 \cdot 5$ $97 \cdot 8)$ compared with $37 \cdot 7 \%(95 \%$ CI $34 \cdot 8-40 \cdot 8)(P=$ $0 \cdot 000$ ). Among individuals born in a Western country, the prevalence estimates according to age ranged from $27 \cdot 4 \%$ to $39 \cdot 5 \%$ in men $v s 27 \cdot 6 \%$ to $48 \cdot 6 \%$ in women. For individuals born in a non-Western country, these figures ranged from $69 \cdot 1 \%$ to $99 \cdot 3 \%$ in men $v s 96 \cdot 6 \%$ to $99 \cdot 5 \%$ in women (Fig. 1).

The prevalence point estimate in individuals with the lowest education level was $49 \cdot 3 \%$ (95\% CI $43 \cdot 9$ $54 \cdot 7)$ compared with $37 \cdot 5 \%(95 \%$ CI $32 \cdot 8-42 \cdot 4)$ in people with a college/university diploma/degree $(P=$ 0.001). People living in the North-West region had the lowest prevalence estimate (Table 1, Fig. 2: $30 \cdot 1 \%$ (95\% CI 24.9-35.8), whereas in the South-East and Paris regions prevalence estimates were $45 \cdot 2 \%(95 \%$ CI $39 \cdot 4-51 \cdot 0)$ and $62 \cdot 6 \%(95 \%$ CI 52.3-71.9), respectively. There were no statistical differences in prevalence estimates when looking at socio-professional categories, employment status or complementary health insurance cover (Table 1).

In the Poisson multivariate regression, we introduced the variables found to be significant in univariate analysis and forced the 'socio-professional category' variable into the model (redefined after collapsing the six-level variable into a four-level one). The multivariate model included age, sex, birthplace (country of origin), education level, complementary health insurance, region of residence and socioprofessional category. We did not find any significant terms of interaction between variables, and only 'complementary health insurance' was not retained in the final model ( $P$-value of 0.98$)$. CMV seropositivity was found to be independently associated with a non-Western country birthplace, female sex, age $\geqslant 25$ 
Table 1. Estimated seroprevalence of CMV infection, univariate analysis, French metropolitan population aged 15 49 years, 2010

\begin{tabular}{|c|c|c|c|c|c|c|}
\hline & $\begin{array}{l}\text { Sample } \\
\text { size }\end{array}$ & $\begin{array}{l}\text { Prevalence } \\
\text { estimate }(\%)\end{array}$ & $95 \% \mathrm{CI}$ & $\begin{array}{l}\text { Prevalence } \\
\text { ratio* }\end{array}$ & $\begin{array}{l}95 \% \\
\text { CI }\end{array}$ & $P$-value \\
\hline Total & 2536 & $41 \cdot 9$ & $38 \cdot 4-45 \cdot 5$ & & & \\
\hline Sex & 2536 & & & & & \\
\hline Male & 1230 & $39 \cdot 3$ & $34 \cdot 9-43 \cdot 8$ & Ref & - & \\
\hline Female & 1306 & $45 \cdot 6$ & $40 \cdot 9-60 \cdot 3$ & $1 \cdot 2$ & $1 \cdot 0-1 \cdot 3$ & $0 \cdot 03$ \\
\hline Age (years) & 2536 & & & & & \\
\hline $15-24$ & 1022 & $28 \cdot 8$ & $25 \cdot 1-32 \cdot 8$ & Ref & - & \\
\hline $25-34$ & 751 & $44 \cdot 4$ & $39 \cdot 0-49 \cdot 8$ & $1 \cdot 5$ & $1 \cdot 3-1 \cdot 8$ & $0 \cdot 000$ \\
\hline $35-49$ & 763 & $47 \cdot 6$ & $43 \cdot 2-52 \cdot 1$ & $1 \cdot 7$ & $1 \cdot 5-1 \cdot 9$ & $0 \cdot 000$ \\
\hline Birth place & 2534 & & & & & \\
\hline France or Western country & 2400 & $37 \cdot 7$ & $34 \cdot 8-40 \cdot 8$ & Ref & - & \\
\hline Non-Western country & 134 & $93 \cdot 7$ & $83 \cdot 5-97 \cdot 8$ & $2 \cdot 5$ & $2 \cdot 3-2 \cdot 7$ & $0 \cdot 000$ \\
\hline Education $^{\dagger}$ & 2485 & & & & & \\
\hline$\geqslant 2$ years of higher education & 1080 & $37 \cdot 5$ & $32 \cdot 8-42 \cdot 4$ & Ref & - & \\
\hline High school & 606 & $39 \cdot 7$ & $33 \cdot 2-46 \cdot 5$ & $1 \cdot 1$ & $0 \cdot 9-1 \cdot 3$ & $0 \cdot 55$ \\
\hline Elementary/middle school & 799 & $49 \cdot 3$ & $43 \cdot 9-54 \cdot 7$ & $1 \cdot 3$ & $1 \cdot 1-1 \cdot 5$ & $0 \cdot 001$ \\
\hline Socio-professional category $^{\dagger}$ & 2517 & & & & & \\
\hline Managerial, intellectual occupations & 332 & $36 \cdot 6$ & $28 \cdot 6-45 \cdot 3$ & Ref & - & \\
\hline Intermediate occupations & 455 & $35 \cdot 4$ & $30 \cdot 5-40 \cdot 6$ & $1 \cdot 0$ & $0 \cdot 8-1 \cdot 2$ & $0 \cdot 79$ \\
\hline Employees & 760 & $45 \cdot 6$ & $40 \cdot 8-50 \cdot 3$ & $1 \cdot 3$ & $1 \cdot 0-1 \cdot 6$ & $0 \cdot 06$ \\
\hline Workers & 288 & $46 \cdot 0$ & $38 \cdot 3-53 \cdot 9$ & $1 \cdot 3$ & $1 \cdot 0-1 \cdot 6$ & $0 \cdot 08$ \\
\hline Farmers-craftsmen & 157 & $47 \cdot 9$ & $35 \cdot 5-60 \cdot 5$ & $1 \cdot 3$ & $0 \cdot 9-1 \cdot 9$ & $0 \cdot 15$ \\
\hline No professional qualification & 525 & $40 \cdot 6$ & $33 \cdot 4-48 \cdot 3$ & $1 \cdot 1$ & $0 \cdot 8-1 \cdot 5$ & $0 \cdot 45$ \\
\hline Current employment status ${ }^{\dagger}$ & 2534 & & & & & \\
\hline Employed & 1756 & $41 \cdot 5$ & $37 \cdot 6-45 \cdot 4$ & Ref & - & \\
\hline Inactive & 606 & $42 \cdot 2$ & $35 \cdot 6-49 \cdot 0$ & $1 \cdot 0$ & $0 \cdot 9-1 \cdot 2$ & $0 \cdot 85$ \\
\hline Unemployed & 172 & $47 \cdot 4$ & $36 \cdot 5-58 \cdot 6$ & $1 \cdot 1$ & $0 \cdot 9-1 \cdot 5$ & $0 \cdot 29$ \\
\hline Complementary health insurance & 2490 & & & & & \\
\hline Yes & 2224 & $40 \cdot 4$ & $36 \cdot 9-44 \cdot 1$ & Ref & - & \\
\hline No & 266 & $49 \cdot 3$ & $36 \cdot 2-62 \cdot 5$ & $1 \cdot 2$ & $0 \cdot 9-1 \cdot 6$ & $0 \cdot 14$ \\
\hline Region & 2536 & & & & & \\
\hline North-West & 501 & $30 \cdot 1$ & $24 \cdot 9-35 \cdot 8$ & Ref & - & \\
\hline Paris \& suburbs & 316 & $62 \cdot 6$ & $52 \cdot 3-71 \cdot 9$ & $2 \cdot 1$ & $1 \cdot 6-2 \cdot 7$ & $0 \cdot 000$ \\
\hline North-East & 775 & $35 \cdot 5$ & $29 \cdot 5-42 \cdot 0$ & $1 \cdot 2$ & $0 \cdot 9-1 \cdot 5$ & $0 \cdot 17$ \\
\hline South-East & 624 & $45 \cdot 2$ & $39 \cdot 4-51 \cdot 0$ & $1 \cdot 5$ & $1 \cdot 2-1 \cdot 9$ & $0 \cdot 000$ \\
\hline South-West & 320 & $34 \cdot 9$ & $26 \cdot 7-44 \cdot 0$ & $1 \cdot 2$ & $0 \cdot 9-1 \cdot 6$ & $0 \cdot 34$ \\
\hline
\end{tabular}

* Adjusted for age, sex and region of residence.

$\dagger$ Highest parents' education level and socio-professional category were used for people under 18 years of age.

+ Inactive people are defined as people who are neither in employment nor unemployed: students, retired people, people engaged in activities in the household, with an incapacity for employment, etc.

years, education level up to middle-school, lower socio-professional categories and residing in Paris, the South-East or the North-East regions (Table 2).

\section{DISCUSSION}

This is the first study in France looking at CMV seroprevalence, using a nationally representative, population-based sample. It yielded national estimates of CMV seroprevalence in metropolitan France for residents aged $15-49$ years, with a national point estimate of $41.9 \%$. Our main findings showed different rates between men and women, respectively, 39.3\% and $45 \cdot 6 \%$. The highest prevalence rates (over 96\%) were in women born in a non-Western country, irrespective of their age, and the lowest in individuals aged 15-24 years born in a Western country $(27 \%$ for both men and women). The prevalence was higher in individuals living in the Paris region (62.6\%) and in those with a lower educational level (49.3\%). 


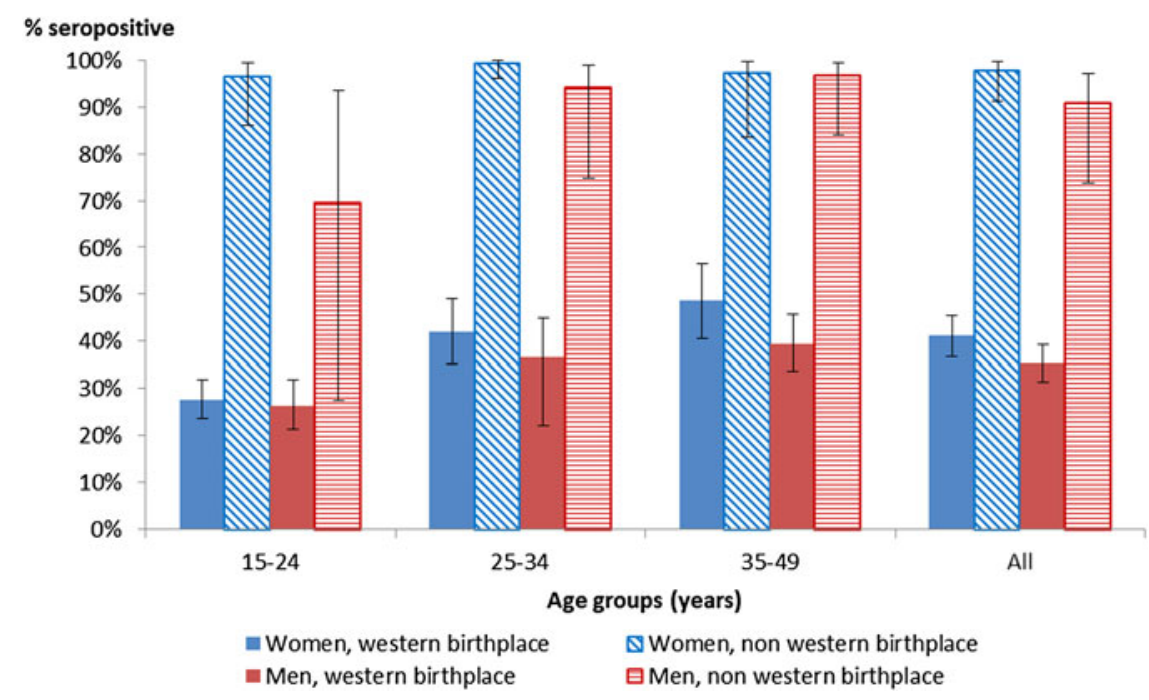

Fig. 1. CMV infection seroprevalence by age-group, sex and birthplace, French metropolitan population aged $15-49$ years, 2010.

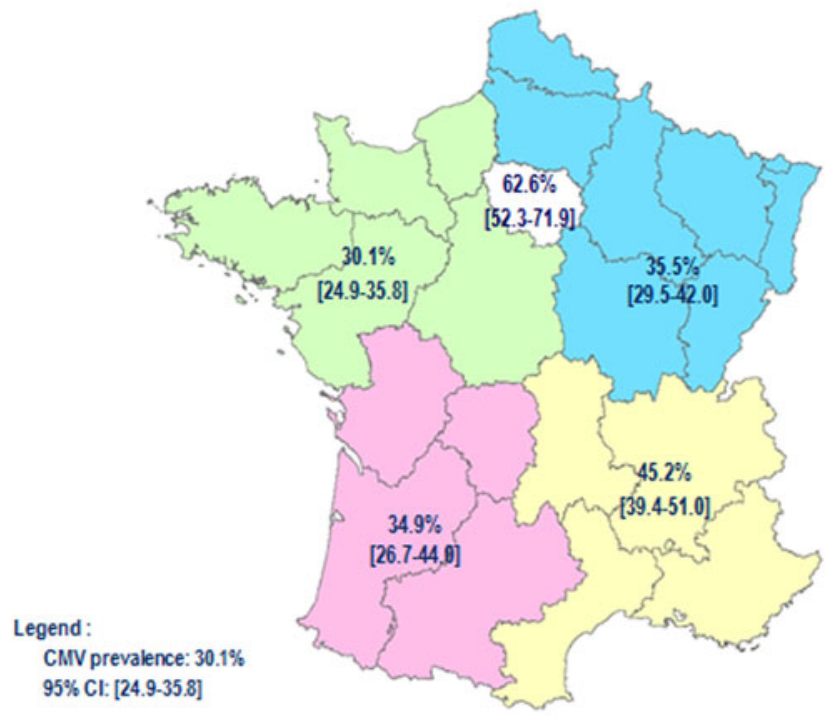

Fig. 2. CMV infection seroprevalence according to region of residence, French metropolitan population aged 15-49 years, 2010.

Our findings reinforced prevalence results found in previous surveys conducted in France, targeted at specific sub-populations such as pregnant women or healthcare workers [22-24]. Furthermore, our prevalence estimates were comparable with those obtained in national surveys conducted in the general populations of other Western countries, such as the USA, the Netherlands and Australia [2, 27, 28]. Consistent with their findings, we identified sex, age, country of origin and educational level as factors independently associated with CMV seropositivity.
One limitation of our study was the survey setting (private medical laboratories), which prevented us from asking questions about more personal issues, such as home crowding and household income. These two factors have been previously described to be independently associated with CMV seropositivity in the literature $[2,27]$. We had to use proxies for household income level such as socio-professional categories, current employment status and complementary health insurance, and we found an association between higher seropositivity and the absence of a 
Table 2. Poisson regression final model of factors independently associated with CMV prevalence, French metropolitan population aged $15-49$ years, 2010

\begin{tabular}{|c|c|c|c|c|c|c|}
\hline & $\begin{array}{l}\text { Sample } \\
\text { size }\end{array}$ & $\begin{array}{l}\text { Prevalence } \\
\text { estimate }(\%)\end{array}$ & $95 \% \mathrm{CI}$ & $\begin{array}{l}\text { Adjusted } \\
\text { prevalence } \\
\text { ratio* }\end{array}$ & $95 \% \mathrm{CI}$ & $P$-value \\
\hline Total & 2536 & $41 \cdot 9$ & $38 \cdot 4-45 \cdot 5$ & & & \\
\hline Sex & 2536 & & & & & \\
\hline Male & 1230 & $39 \cdot 3$ & $34 \cdot 9-43 \cdot 8$ & Ref & - & \\
\hline Female & 1306 & $45 \cdot 6$ & $40 \cdot 9-60 \cdot 3$ & $1 \cdot 2$ & $1 \cdot 0-1 \cdot 3$ & $0 \cdot 03$ \\
\hline Age (years) & 2536 & & & & & \\
\hline $15-24$ & 1022 & $28 \cdot 8$ & $25 \cdot 1-32 \cdot 8$ & Ref & - & \\
\hline $25-34$ & 751 & $44 \cdot 4$ & $39 \cdot 0-49 \cdot 8$ & $1 \cdot 5$ & $1 \cdot 3-1 \cdot 8$ & $0 \cdot 000$ \\
\hline $35-49$ & 763 & $47 \cdot 6$ & $43 \cdot 2-52 \cdot 1$ & $1 \cdot 7$ & $1 \cdot 5-2 \cdot 0$ & $0 \cdot 000$ \\
\hline Birth place & 2534 & & & & & \\
\hline France or Western country & 2400 & $37 \cdot 7$ & $34 \cdot 8-40 \cdot 8$ & Ref & - & \\
\hline Non-Western country & 134 & $93 \cdot 7$ & $83 \cdot 5-97 \cdot 8$ & $2 \cdot 4$ & $1 \cdot 7-3 \cdot 3$ & $0 \cdot 000$ \\
\hline Education $^{\dagger}$ & 2485 & & & & & \\
\hline$\geqslant 2$ years higher education & 1080 & $37 \cdot 5$ & $32 \cdot 8-42 \cdot 4$ & Ref & - & \\
\hline High school & 606 & $39 \cdot 7$ & $33 \cdot 2-46 \cdot 5$ & $1 \cdot 1$ & $0 \cdot 9-1 \cdot 2$ & $0 \cdot 66$ \\
\hline Elementary/middle school & 799 & $49 \cdot 3$ & $43 \cdot 9-54 \cdot 7$ & $1 \cdot 2$ & $1 \cdot 0-1 \cdot 4$ & $0 \cdot 001$ \\
\hline Socio professional category & 2517 & & & & & \\
\hline $\begin{array}{l}\text { Managerial, intellectual and } \\
\text { intermediate occupations }\end{array}$ & 787 & $35 \cdot 9$ & $30 \cdot 8-41 \cdot 3$ & Ref & - & \\
\hline Employees & 760 & $45 \cdot 6$ & $40 \cdot 8-50 \cdot 3$ & $1 \cdot 2$ & $1 \cdot 0-1 \cdot 4$ & $0 \cdot 05$ \\
\hline Workers/farmers/craftsmen & 445 & $46 \cdot 8$ & $39 \cdot 8-53 \cdot 8$ & $1 \cdot 3$ & $1 \cdot 0-1 \cdot 6$ & $0 \cdot 02$ \\
\hline No professional qualification & 525 & $40 \cdot 6$ & $33 \cdot 4-48 \cdot 3$ & $1 \cdot 4$ & $1 \cdot 1-1 \cdot 7$ & $0 \cdot 002$ \\
\hline Region & 2536 & & & & & \\
\hline North-West & 501 & $30 \cdot 1$ & $24 \cdot 9-35 \cdot 8$ & Ref & - & \\
\hline Paris \& suburbs & 316 & $62 \cdot 6$ & $52 \cdot 3-71 \cdot 9$ & 1.9 & $1 \cdot 6-2 \cdot 3$ & $0 \cdot 000$ \\
\hline North-East & 775 & $35 \cdot 5$ & $29 \cdot 5-42 \cdot 0$ & $1 \cdot 2$ & $1 \cdot 0-1 \cdot 5$ & $0 \cdot 06$ \\
\hline South-East & 624 & $45 \cdot 2$ & $39 \cdot 4-51 \cdot 0$ & $1 \cdot 6$ & $1 \cdot 3-1 \cdot 9$ & $0 \cdot 000$ \\
\hline South-West & 320 & $34 \cdot 9$ & $26 \cdot 7-44 \cdot 0$ & $1 \cdot 2$ & $0 \cdot 9-1 \cdot 6$ & $0 \cdot 19$ \\
\hline
\end{tabular}

* Adjusted for age, sex and region of residence.

$\dagger$ Highest parents' education level and socio-professional category were used for people under 18 years of age.

professional qualification and lowest possible educational level.

Due to the limitation in age groups included in our study, we could not document when seropositive individuals became infected with CMV during childhood. Although the cross-sectional nature of our study limits interpretation in terms of force of infection according to age, our data show an increase in seroprevalence during childbearing age for women born in France and other Western countries: $<30 \%$ of them were CMV positive before 25 years of age, but nearly $50 \%$ above this age. Young seronegative women $(>70 \%)$ are consequently at higher risk of primary CMV infection during pregnancy.

In 2010, Cannon et al. published an extensive review of literature on CMV seroprevalence surveys conducted between 1966 and 2008, most of them targeting special sub-groups of population [29]. The authors highlighted that CMV seropositivity was relatively common among women of childbearing age, ranging from $45 \%$ to $100 \%$. They confirmed the main risk factors associated with CMV seropositivity, including increased prevalence with age, female gender, belonging to a non-white ethnic group and lower socio-economic status. They pointed out substantial variations in CMV seroprevalence across continents, but also within them. The lowest prevalence rates were in Western Europe and USA, and the highest in South America, Africa and Asia. Within the USA, they showed prevalence discrepancies between different regions, as we did in our study in France.

As countries become more developed, one expects the level of hygiene and wealth to improve, and the CMV-IgG seroprevalence at the beginning of childbearing age to decrease [30, 31]. Regarding the risk of infection, unfortunately, both awareness and knowledge of 
CMV infection are quite low in the general population, especially in pregnant women. This is mainly due to practitioners' lack of awareness and knowledge about CMV infection and its consequences, and in some maternities, to insufficient primary prevention through women's education programs about CMV transmission and basic hygiene preventive measures [19, 32]. The role of screening for CMV has been widely debated in recent years, but there is no consensus to date on the relevancy of screening pregnant women for CMV seronegativity [32-34]. Neither is there any current adequate treatment against CMV during pregnancy, nor an available vaccine [35]. Therefore, preventive measures against CMV infection during pregnancy are of crucial importance, and since the 2000s, national colleges of obstetricians and gynaecologists together with national public health authorities have encouraged counselling pregnant women on hygiene practices and providing information on CMV transmission routes, in order to reduce the risks linked to exposure to saliva and urine of toddlers [36]. These recommendations are targeted both at the mothers and their partners, as well as at pregnant women caring for children $<3$ years of age [37]. Furthermore, preconceptional immunity to CMV provides only incomplete protection against intrauterine transmission, as immune women may be infected with a new or different CMV strain [14]. In addition, using a population-based prediction model, de Vries et al. [18] showed that, paradoxically, maternal seropositivity might be a risk factor for congenital CMV infection, as they identified non primary maternal CMV infections responsible for the majority of congenital infections, for both high and low seroprevalent populations. Thus, to avoid any adverse outcomes that may occur in infected children born to women seropositive prior to pregnancy, counselling should be provided to all pregnant women. In France, CMV screening during pregnancy is therefore not recommended; but the importance of information on prevention of transmission has been stressed by the French National Agency for Accreditation and Evaluation in Healthcare (Haute Autorité de Santé) [38].

\section{CONCLUSION}

Even if behavioural changes obtained through health counselling should lead to a decrease of congenital CMV infections, there is still an urgent need for improved treatments and vaccine development. CMV seroprevalence data could be used to power interventional studies for pregnant women with proven primary $\mathrm{CMV}$ infection and to plan strategies against congenital CMV infection. Nevertheless, the best option remains an effective vaccine to be given to children and teenagers, and hopes are high that candidate vaccines currently in clinical evaluation, including live attenuated, protein subunit, DNA and viral-vectored approaches, will be successful [36, 39].

\section{ACKNOWLEDGEMENTS}

We are grateful to all patients who accepted to participate in this study, and to the biologists for collecting specimens and informing the survey questionnaires.

\section{DECLARATION OF INTEREST}

We report no conflicts of interest.

\section{REFERENCES}

1. Kenneson A, Cannon MJ. Review and meta-analysis of the epidemiology of congenital cytomegalovirus (CMV) infection. Reviews in Medical Virology 2007; 17: 253-276.

2. Bate SL, Dollard SC, Cannon MJ. Cytomegalovirus seroprevalence in the United States: the national health and nutrition examination surveys, 1988-2004. Clinical Infectious Diseases 2010; 50: 1439-1447.

3. Dar L, et al. Congenital cytomegalovirus infection in a highly seropositive semi-urban population in India. Pediatric Infectious Diseases Journal 2008; 27: 841-843.

4. Hamprecht $\mathbf{K}$, et al. Epidemiology of transmission of cytomegalovirus from mother to preterm infant by breastfeeding. Lancet 2001; 357: 513-518.

5. Cohen JI, Corey GR. Cytomegalovirus infection in the normal host. Medicine (Baltimore) 1985; 64: 100-114.

6. Stagno S, et al. Breast milk and the risk of cytomegalovirus infection. New England Journal of Medicine 1980; 302: 1073-1076.

7. Pass RF, et al. Increased rate of cytomegalovirus infection among parents of children attending day-care centers. New England Journal of Medicine 1986; 314: 1414-1418.

8. Marshall BC, Adler SP. The frequency of pregnancy and exposure to cytomegalovirus infections among women with a young child in day care. American Journal of Obstetrics and Gynecology 2009; 200: 163. e1-163.e5.

9. Collier AC, et al. Cytomegalovirus infection in women attending a sexually transmitted disease clinic. Journal of Infectious Diseases 1990; 162: 46-51.

10. Sohn YM, et al. Cytomegalovirus infection in sexually active adolescents. Journal of Infectious Diseases 1991; 163: $460-463$.

11. Dollard SC, Grosse SD, Ross DS. New estimates of the prevalence of neurological and sensory sequelae and 
mortality associated with congenital cytomegalovirus infection. Reviews in Medical Virology 2007; 17: 355-363.

12. Grosse SD, Ross DS, Dollard SC. Congenital cytomegalovirus (CMV) infection as a cause of permanent bilateral hearing loss: a quantitative assessment. Journal of Clinical Virology 2008; 41: 57-62.

13. Fowler KB, Stagno S, Pass RF. Interval between births and risk of congenital cytomegalovirus infection. Clinical Infectious Diseases 2004; 38: 1035-1037.

14. Fowler KB, Stagno S, Pass RF. Maternal immunity and prevention of congenital cytomegalovirus infection. Journal of the American Medical Association 2003; 289: 1008-1111.

15. Townsend CL, et al. Long term outcomes of congenital cytomegalovirus infection in Sweden and in the United Kingdom. Clinical Infectious Diseases 2013; 56: 1232-1239.

16. Wang C, et al. Attribution of congenital cytomegalovirus infection to primary versus non-primary maternal infection. Clinical Infectious Diseases 2011; 52: e11-e13.

17. Mussi-Pinhata MM, et al. Birth prevalence and natural history of congenital cytomegalovirus infection in a highly seroimmune population. Clinical Infectious Diseases 2009; 15: 522-8.

18. de Vries JJC, et al. The apparent paradox of maternal seropositivity as a risk factor for congenital cytomegalovirus infection: a population-based prediction model. Reviews in Medical Virology 2013; 23: 241-9.

19. Demmler-Harrison GJ. Congenital cytomegalovirus: public health action towards awareness, prevention, and treatment. Journal of Clinical Virology 2009; 46: S1-S5.

20. Arvin AM, et al. Vaccine development to prevent cytomegalovirus disease: report from the National Vaccine Advisory Committee. Clinical Infectious Diseases 2004; 39: 233-239.

21. Lepoutre A, et al. Seroprevalence of vaccine preventable diseases and of five other infectious diseases in France. Results of two national surveys, 2008-2010. Bulletin Epidémiologique Hebdomadaire 2013; 41-42: 526-34.

22. Gratacap-Cavallier B, et al. Cytomegalovirus seroprevalence in French pregnant women: parity and place of birth as major predictive factors. European Journal of Epidemiology 1998; 14: 147-152.

23. Gouarin S, et al. Congenital HCMV infection: a collaborative and comparative study of virus detection in amniotic fluid by culture and by PCR. Journal of Clinical Virology 2001; 21: 47-55.

24. Lepage $\mathbf{N}$, et al. Cytomegalovirus seroprevalence in exposed and unexposed populations of hospital employees. European Journal of Clinical Microbiology and Infectious Diseases 2011; 30: 65-70.
25. Osborne K, Weinberg J, Miller E. The European Sero-Epidemiology Network (ESEN). Eurosurveillance 1997; 2: 93-96.

26. Zou G. A modified poisson regression approach to prospective studies with binary data. American Journal of Epidemiology 2004; 159: 702-706.

27. Korndewal MJ, et al. Cytomegalovirus infection in the Netherlands: seroprevalence, risk factors, and implications. Journal of Clinical Virology 2015; 63: 53-58.

28. Seale H, et al. National serosurvey of cytomegalovirus in Australia. Clinical and Vaccine Immunology 2006; 13: $1181-1184$.

29. Cannon MJ, Schmid DS, Hyde TB. Review of cytomegalovirus seroprevalence and demographic characteristics associated with infection. Reviews in Medical Virology 2010; 20: 202-213.

30. De Ory F, et al. Is there a change in cytomegalovirus seroepidemiology in Spain? European Journal of Epidemiology 2004; 19: 85-89.

31. Lübeck PR, Doerr HW, Rabenau HF. Epidemiology of human cytomegalovirus (HCMV) in an urban region of Germany: what has changed? Medical Microbiology and Immunology 2010; 199: 53-60.

32. Forsgren M. Prevention of congenital and perinatal infections. Eurosurveillance 2009; 14: 2-4.

33. Peckham C, et al. Screening options for prevention of congenital cytomegalovirus infection. Journal of Medical Screening 2001; 8: 119-24.

34. Walker S, et al. Cytomegalovirus in pregnancy: to screen or not to screen. BMC Pregnancy and Childbirth 2013; 13: 96.

35. Schleiss MR, Plotkin SA. Cytomegalovirus vaccines. In: Plotkin SA, Orenstein WA, Offit PA, eds. Vaccines, 6th edn. Philadelphia: Saunders Elsevier Company, 2013, pp. 1032-1041.

36. American College of Obstetricians and Gynecologists. Perinatal viral and parasitic infections. ACOG Practice Bulletin 20. International Journal of Gynaecology and Obstetrics 2002; 76: 95-107.

37. Vauloup-Fellous $\mathbf{C}$, et al. Does hygiene counselling have an impact on the rate of CMV primary infection during pregnancy? Results of a 3-year prospective study in a French hospital. Journal of Clinical Virology 2009; 46 (Suppl. 4): S49-S53.

38. Haute autorité de santé (French National Agency for Accreditation and Evaluation in Healthcare). Assessment of screening for cytomegalovirus (CMV) infection in pregnant women in France, 2004. (http://www.hassante.fr/portail/upload/docs/application/pdf/cytomegalovirus_abstract.pdf). Accessed 2 September 2016.

39. McVoy MA. Cytomegalovirus vaccines. Clinical Infectious Diseases 2013; 57(Suppl.4): S196-S199. 